\title{
Breathing patterns during sleep in patients with nocturnal asthma
}

\author{
A D MORGAN, G B RHIND, J J CONNAUGHTON, J R CATTERALL, \\ C M SHAPIRO, N J DOUGLAS
}

From the Rayne Laboratory and the Departments of Respiratory Medicine and Psychiatry, University of Edinburgh

ABSTRACT Breathing patterns early and late in the night, at the same sleep stage, were compared in six healthy subjects and 15 adults with nocturnal asthma, to try to identify changes of overnighe bronchoconstriction, and breathing patterns at different sleep stages, to see whether there were changes related to sleep stages that were indicative of bronchoconstriction. Despite an average $31 \%$ fall in $\mathrm{FEV}_{1}$ overnight in the patients with asthma, neither breathing frequency nor expiratory time which might be expected to change during bronchoconstriction, was different early in the night from late in the night, nor did they differ between sleep stages. There was no evidence of asynchronouso movement of the chest and abdomen in any patient. This study did not identify any abnormality of breathing pattern that would indicate the development of nocturnal asthma without the need too awaken the patient.

\section{Introduction}

Nocturnal wheeze and cough are common problems for many asthmatic patients. These symptoms result from overnight bronchoconstriction, which is caused at least in part by sleep itself ${ }^{12}$ and perhaps by rapid eye movement (REM) sleep. ${ }^{3}$ Most studies of nocturnal asthma have been based on the measurement of expiratory flow rates, which means wakening the patient and thus interferes with sleep, one of the important factors in the production of nocturnal bronchoconstriction. We have therefore examined the breathing pattern of sleeping asthmatic patients to see whether we could identify changes that would indicate developing airflow obstruction without the need to interrupt sleep.

Bronchoconstriction in asthma has been reported to be associated with tachypnoea ${ }^{4-6}$ and with either relative $^{7}$ or absolute ${ }^{8}$ prolongation of expiratory time. We have therefore examined the hypothesis that bronchoconstriction might be detectable in sleeping asthmatic subjects by changes in respiratory timing, which we have compared both at different sleep stages, to try to identify any REM sleep bronchoconstriction, and early and late in the night, to try to identify overnight bronchoconstriction.

Address for correspondence: Dr A D Morgan, Department of Respiratory Medicine, Westminster Hospital, London SWIP 2AP. (Reprints will not be available.)

Accepted 18 February 1987

\section{Methods}

We studied 15 asthmatic patients (11 men and foup $\overrightarrow{\vec{p}}$ women; mean age 34 (range 18-69) years), all of whom complained of nocturnal wheeze. All increased their $\mathrm{FEV}_{1}$ by more than $20 \%$ after bronchodilators and all had been stable for at least four weeks before study. All were receiving bronchodilator inhalers which were withheld for six hours before the study; $1 \mathrm{~b}$ were having inhaled corticosteroid treatment, and two were receiving oral prednisolone in a dosage of $10 \mathrm{~B}$ $\mathrm{mg} /$ day or less. Six healthy men were also studied as controls (mean age 33 (range 23-45) years).

All subjects spent two consecutive nights in the sleep laboratory; the first was for acclimatisation and only data from the second night are reported. FEV and FVC were measured before and after sleep inp triplicate and the highest level is reported. In nines patients thoracic and abdominal movement was determined by an induction stethogram (Respitrace Ardsley, New York), while in six asthmatic patients and the six normal subjects respiratory time was determined by an anteroposterior chest stethogram. Ear oxygen saturation was measured by a Hewletito Packard 47201A Ear Oximeter. ${ }^{10}$ These signals pluș electroencephalogram, electro-oculogram, and elec $\overrightarrow{\mathbb{D}}$ tromyogram from our standard electrode placement $\frac{8}{0}$ were recorded on a 16 channel recorder (Neuroscribe $\frac{\odot}{\sigma}$ SLE, Croydon) running at $15 \mathrm{~mm} / \mathrm{s}$. Sleep was staged by conventional criteria. ${ }^{11}$ 
Breathing patterns were compared, firstly between stable stage 2 sleep before 1 am and stable stage 2 sleep after 4 am and, secondly, between REM sleep and the nearest available period of stable non-REM (stage 2, 3, or 4) sleep. With the Respitrace 30-50 breaths were analysed manually from the paper trace at each time under study, whereas with the anteroposterior stethogram 190-240 breaths were analysed by a PDP $11 / 23$ + computer, which had sampled the respiratory signals at $50 \mathrm{~Hz}$ and determined breath periods from maximum and minimum thoracic excursion.

All subjects gave written informed consent to the study, which had approval from the hospital ethical committee. Results are expressed as means with 1 SEM in parentheses. Statistical significance was assessed by Student's paired and unpaired $t$ tests.

\section{Results}

Although the asthmatic and normal subjects spent a similar time in bed, the normal subjects slept for longer (395 (SEM 10) min) than the asthmatic sub-

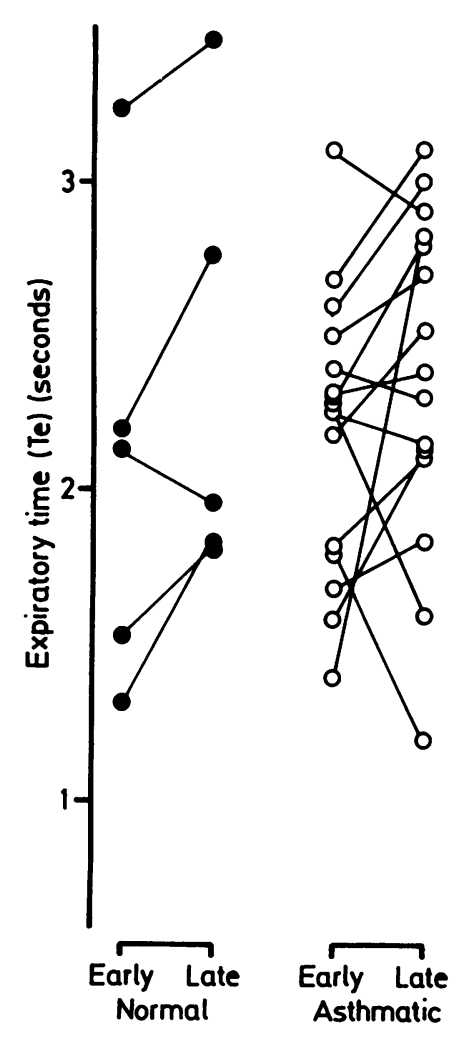

jects (310(15) min; $\mathrm{p}<0.01)$ and the normal subjects had more REM sleep (80(11) v 45(5) min; $\mathrm{p}<0.01$ ). In the asthmatic subjects the $\mathrm{FEV}_{1}$ fell overnight from $2 \cdot 5(0.4)$ litres before sleep to $1 \cdot 7(0.3) 1$ after sleep, with an average fall of $31 \%(3 \%)$ (range $11-65 \%)$.

There was no change in respiratory timing during stage 2 sleep between early and late in the night (breath period (Ttot) before 1 am $4.0(0.2)$ and after 4 am $4 \cdot 2(0 \cdot 1)$ seconds; $p>0 \cdot 15$; expired time (Te) $2 \cdot 2(0 \cdot 1)$ v $2.4(0 \cdot 1) \mathrm{s} ; \mathrm{p}>0.2$; Ti/Ttot $44 \%(2 \%) v$ $42 \%(1 \%) ; p>0.2-$ see figure). All five asthmatic subjects whose $F E V_{1}$ fell overnight by 1 litre or more (mean $\mathrm{FEV}_{1}$ before sleep 3.8, after sleep $2.3 \mathrm{l}$ ) had a longer Te late than early in the night $(2 \cdot 3(0 \cdot 2) v$ $2 \cdot 6(0.2) \mathrm{s})$. Te tended to increase, however, in the six normal subjects also $(2.1(0.3)$ v $2.4(0.3) \mathrm{s} ; \mathrm{p}>0.1)$ and there was no significant difference between the change in Te overnight in these five asthmatic patients and that in the six normal subjects. There were no other consistent differences between early and late in the night in the breathing pattern in these five asthmatic subjects.
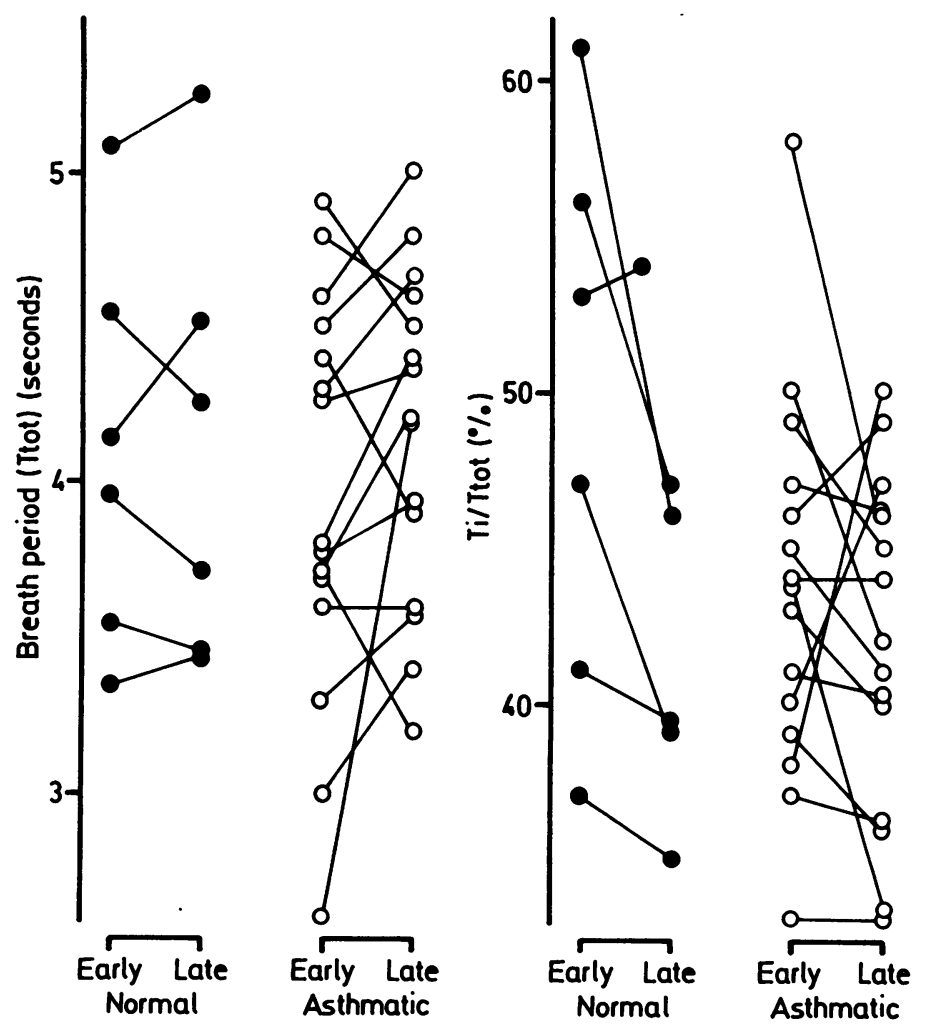

Expiratory time, breath period, and duty cycle ratio (Ti/Tot) early (before 1 am) and late (after 4 am) in the night in normal subjects (solid symbols) and asthmatic subjects (open symbols). 
We found no differences between non-REM and REM sleep in respiratory timing either in the normal subects or in the asthmatic patients (normal subjects: Ttot (seconds), non-REM 3.5(0.7) versus REM 3.1 (0.05); p > 0.05; Te (s), 2.1(0.5) v 1.8(0.4); p > $0 \cdot 1$; Ti/Ttot (\%), 33(8) v 38(8); $\mathrm{p}>0.05$; asthmatics: Ttot (s), 3.6(0.3) v 3.5(0.3), p > 0.1; Te (s), 2.1 (0.2) v 2.0(0.2); $\mathrm{p}>0.15 ; \mathrm{Ti} / \mathrm{T}$ tot (\%), $40(3)$ v $40(3)$; $\mathrm{p}>0.6)$.

The mean oxygen saturation in the asthmatic subjects when awake was $96 \%(2 \%)$, the lowest oxygen saturation during sleep averaging $88 \%(4 \%)$. There was no correlation between overnight falls in FEV and the degree of nocturnal hypoxaemia.

None of the nine patients studied with the Respitrace showed paradoxical movement of the chest and abdomen at any stage. There were small phase differences between chest and abdominal movement, maximal abdominal excursion always preceding maximal chest excursion; but this lead time was under $13 \%$ of Ttot in each subject at each sleep stage. The mean phase difference was $3.0 \%(1.0 \%)$ of Ttot in awake subjects, $4.8 \%(1.3 \%)$ during nonREM sleep, and $5.3 \%(1.7 \%)$ in REM sleep.

\section{Discussion}

We thus found no abnormality of breathing pattern in sleeping patients with nocturnal asthma that might indicate nocturnal bronchoconstriction. We could therefore not confirm our preliminary report ${ }^{12}$ that expiratory time was prolonged in REM sleep, as might have been expected were REM sleep associated with bronchoconstriction. ${ }^{3}$

Our inability to find any change in breathing pattern may reflect mild bronchoconstriction occurring overnight $\left(31 \%(\right.$ SEM $3 \%)$ fall in FEV $\left._{1}\right)$ or between sleep stages in our patients, as changes in respiratory timing may be more apparent during the moderate or severe bronchoconstriction of acute asthma ${ }^{7}$ than during mild bronchoconstriction. ${ }^{1314}$ We have previously found, however, that a $37 \%$ (SEM 11\%) fall in FEV $_{1}$ produced by histamine inhalation significantly prolongs both $\mathrm{Ti}$ and $\mathrm{Te}{ }^{8}$ Our failure to identify an index of nocturnal bronchoconstriction in sleeping asthmatic subjects is disappointing, as this would have allowed study of the development of nocturnal asthma without disturbing sleep. Issa and Sullivan ${ }^{15}$ recently found phase changes between the chest and abdomen during acute attacks of asthma in sleeping patients. We did not observe any acute attacks in this study as we were trying to identify abnormalities of breathing pattern indicating moderate overnight bronchoconstriction. Neither did we confirm the observation of Tabachnik et al $^{16}$ that abnormal chest wall mechanics with paradox between rib and abdøminal movement occur in asthmatic sub- $\overrightarrow{\vec{\rho}}$ jects during sleep. Such paradox is common in the $\frac{\sigma}{\sigma}$ very young, and our patients were older (18-69 years) than those of Tabachnik et al (12-15 years) and their $\frac{\bar{\omega}}{\bar{\omega}}$ chest walls would be more rigid. Even our younger $\vec{\nabla}$ patients, however, showed no paradox. The study 응 confirms our previous observation ${ }^{12}$ that, contrary to $ळ$ another report, ${ }^{17}$ there is no correlation between the $\vec{\circ}$ extent of nocturnal hypoxaemia and the degree of $\overrightarrow{\vec{H}}$ nocturnal bronchoconstriction.

This study thus suggests that adults with relatively mild nocturnal asthma have no abnormality of $x$ breathing pattern indicative of overnight or sleep $\stackrel{+}{N}$ stage related bronchoconstriction.

We acknowledge the support of the Asthma Research Council and Fisons PLC.

\section{References}

1 Hetzel MR, Clark TJH. Does sleep cause nocturnal $\vec{\oplus}$ asthma? Thorax 1979;34:749-54.

2 Catterall JR, Rhind GB, Stewart IC, Whyte KF, Shapiro CM, Douglas NJ. Effect of sleep deprivation on overnight bronchoconstriction in nocturnal asthma. Thorax 1986;41:676-80.

3 Shapiro CM, Catterall JR, Montgomery I, Raab GM, Douglas NJ. Do asthmatics suffer bronchoconstriction during rapid eye movement sleep? Br Med $\overrightarrow{\vec{O}}$ $J$ 1986;292:1161-4.

4 Mann J, Bradley CA, Antonisen NR. Occlusion pressure in acute bronchospasm caused by methacholine. Respir Physiol 1978;33:339-46.

5 Kelsen SG, Prestel PF, Cherniack NS, Chester EH, Deal EC. Comparison of the respiratory responses to external resistive loading in bronchcoconstriction. J Clin Invest 1981;67:1761-8.

6 Pardy RL, Rivington RN, Milic-Emili J, Mortola JP. Control of breathing in chronic obstructive pulmonary disease. Am Rev Respir Dis 1982;125:6-11.

7 Hillman DR, Prentice L, Finucane KE. The pattern of 윽 breathing in acute severe asthma. Am Rev Respir Dis 1986;133:587-92.

8 Stewart IC, Catterall JR, Wraith PK, Douglas NJ, Flenley DC. Breathing patterns in acute asthma and in 0 bronchoconstriction induced by histamine and meth- $\mathrm{N}$ acholine [abstract]. Am Rev Respir Dis 1984;129:A47. N

9 Douglas NJ, Calverley PMA, Leggett RJE, Brash HM, Flenley DC, Brezinova V. Transient hypoxaemia during steep in chronic bronchitis and emphysema. Lancet $\bullet$ 1979;i:1-4.

10 Douglas NJ, Brash HM, Wraith PK, Calverley PMA, $\stackrel{\leftrightarrow}{?}$ Leggett RJE, Flenley DC. Accuracy, sensitivity to car- 0 boxyhaemoghobin and speed of response of the Hew- $\bar{D}$ lett Packard 47201A ear oximeter. Am Rev Respir Dis $\mathbb{D}$ 1979;119:311-3.

11 Rechtschaffen A, Kales A, eds. A manual of standardised $\stackrel{\mathbb{2}}{\square}$ teminology, techniques and scoring system for sleep ${ }_{2}$ stages of human subjects. Bethesda: National Institute 
of Neurological Disease and Blindness, 1968. (NIH publication No 204.)

12 Catterall JR, Douglas NJ, Calverley PMA, et al. Irregular breathing and hypoxaemia during sleep in chronic stable asthma. Lancet 1982;i:301-4.

13 Tobin MJ, Birch S, Jenouri GA, Sackner MA. Acute effects of aerosolised metaproterenol on breathing pattern of patients with symptomatic bronchial asthma. $J$ Allergy Clin Immunol 1985;76:166-72.

14 Chadha TS, Schneider AW, Birch S, Jenouri G, Sackner MA. Breathing patterns during induced bronchoconstriction. J Appl Physiol 1984;56:1053-9.
15 Issa FG, Sullivan CE. Respiratory muscle activity and thoracoabdominal motion during acute episodes of asthma during sleep. Am Rev Respir Dis 1985;132: 999-1004.

16 Tabachnik E, Muller NL, Levison $\mathrm{H}$, et al. Chest wall mechanics and patterns of breathing during sleep in asthmatic adolescents. Am Rev Respir Dis 1981;124: 269-73.

17 Smith TH, Hudgel DW. Arterial oxygen desaturation during sleep in children with asthma and its relation to airway obstruction and ventilatory drive. Pediatrics 1980;66:746-51. 